\title{
Pharmacokinetics, safety and efficacy from randomized controlled trials of I and 2 mg nicotine bitartrate lozenges (Nicotinell ${ }^{\circledR}$ ) Bertrand Dautzenberg ${ }^{1}$, Mitchell Nides ${ }^{2}$, Jean-Luc Kienzler ${ }^{3}$ and Anne Callens*4
}

Address: ${ }^{1}$ Groupe Hospitalier Pitié-Salpêtrière, Paris, France, ${ }^{2}$ Los Angeles Clinical Trials, Los Angeles, CA, USA, ${ }^{3}$ Novartis Consumer Health S.A., Nyon, Switzerland and ${ }^{4}$ Novartis Santé Familiale, Rueil-Malmaison, France

Email: Bertrand Dautzenberg - bertrand.dautzenberg@psl.aphp.fr; Mitchell Nides - mnides@laclinicaltrials.com; Jean-Luc Kienzler - jeanluc.kienzler@novartis.com; Anne Callens* - anne.callens@novartis.com

* Corresponding author

Published: 8 October 2007

BMC Clinical Pharmacology 2007, 7:II doi:10.1 186/1472-6904-7-II
Received: 7 December 2006

Accepted: 8 October 2007

This article is available from: http://www.biomedcentral.com/I472-6904/7/II

(C) 2007 Dautzenberg et al; licensee BioMed Central Ltd.

This is an Open Access article distributed under the terms of the Creative Commons Attribution License (http://creativecommons.org/licenses/by/2.0), which permits unrestricted use, distribution, and reproduction in any medium, provided the original work is properly cited.

\begin{abstract}
Background: The use of nicotine replacement therapy (NRT) can almost double the chances of success for smokers to quit. Nevertheless, there is still a considerable number of cessation attempts that are made without any treatment. This novel oral formulation, (lozenge containing nicotine bitartrate dihydrate) has been developed to enlarge the offer for efficient smoking cessation drug therapies, assuming that increasing treatment options will bring more smokers to find the support they personally need to stop smoking.
\end{abstract}

Methods: Three pharmacokinetic (PK), one safety and two efficacy studies were carried out with Nicotinell lozenges. PK trials were: (I) a single-dose, three-way crossover study comparing I and $2 \mathrm{mg}$ lozenges with 2 mg nicotine gum; (2) a multiple-dose, two-way crossover study comparing I $\mathrm{mg}$ lozenge with $2 \mathrm{mg}$ gum; (3) a multiple-dose, three-way crossover study comparing I and $2 \mathrm{mg}$ lozenges with $4 \mathrm{mg}$ gum. Safety trial: (4) a single dose study to assess the safety of swallowing up to 12 lozenges containing I mg nicotine. Efficacy trials: two efficacy studies in (5) France and (6) the USA, including more than 900 smokers followed-up for up to one year, conducted with the I mg lozenge.

Results: The results of the individual PK trials showed that the I $\mathrm{mg}$ Nicotinell lozenge is bioequivalent to $2 \mathrm{mg}$ polacrilex gum, as demonstrated by similar blood PK parameters ( $\left.t_{\max }, C_{\max }, A U C\right)$. The 2 mg lozenge was found to deliver quantities of nicotine that were intermediate between those delivered by 2 and $4 \mathrm{mg}$ polacrilex gum.

The short-term efficacy of the I mg lozenge in comparison with placebo was also demonstrated with significantly more subjects continuously abstinent from smoking with active lozenges on week 6 in two different populations: moderate to heavy smokers (FTND between 4 and 7) OR = 1.72 [95\% Cl: I.05-2.80]; heavy to very heavy smokers (FTND 6 and over) $\mathrm{OR}=2.87$ [95\% Cl: I.18-6.97].

Nicotinell lozenges were found to be safe with mainly mild and reversible adverse events. The safety of the I mg lozenge formulation, even when misused was also demonstrated.

Conclusion: The data presented in this review demonstrate high nicotine bioavailability, excellent safety profile and proven short-term efficacy of Nicotinell lozenges. At nominal equivalent doses I and 2 mg Nicotinell lozenges were shown to deliver larger amounts of bioavailable nicotine compared to the nicotine polacrilex gum. According to the data developed here, the systemic exposure to nicotine could be ranked: $4 \mathrm{mg}$ polacrilex gum $>2$ mg Nicotinell lozenge $>$ I $\mathrm{mg}$ Nicotinell lozenge $=2 \mathrm{mg}$ polacrilex gum. 
Adverse events observed during the clinical trials were mild or moderate in severity, transient and completely reversible. With respect to efficacy in smoking cessation, significantly higher continuous abstinence rates were achieved with lozenge compared to placebo. In conclusion, Nicotinell lozenges offer a valuable addition to the therapeutic armamentarium available for smoking cessation.

\section{Background}

Smoking is still the largest preventable cause of death and disease in the developed world and increases the risk for cancer, cardiovascular and lung diseases, among others [1-3]. Accordingly, smoking cessation provides immediate and lasting benefits to public health [4-6]. However, relatively few smokers succeed in quitting each year [7]. Nicotine replacement therapy (NRT) helps smokers quit by providing nicotine at levels usually lower than those obtained through smoking and without the toxins contained in tobacco smoke. NRT can reduce the craving for nicotine and the nicotine withdrawal symptoms which might otherwise jeopardize the smoking cessation efforts [8]. NRT has a well established success record [9] and its use is endorsed by health authorities [4,10-12].

Several forms of NRT are available for smokers to choose from, according to their specific needs and preferences $[8,13]$. Beside nicotine patches, which deliver nicotine slowly and continuously through the skin, a number of acute dosage forms have been developed, which allow smokers to self-administer the amount of nicotine needed, in order to achieve a consistent concentration of nicotine in the blood, and to ward off acute urges to smoke ('rescue medication' use) [14]. The first available acute dosage form was nicotine-polacrilex chewing-gum, which was launched in the 1980s. More recent additions are the vapor inhaler, sublingual tablet, lozenge (all for oral nicotine administration), and nasal spray (uptake via the nasal mucosa) [15].

The efficacy and safety of nicotine lozenges containing 2 or $4 \mathrm{mg}$ of nicotine coupled to a polacrilex resin, from which it is released upon dissolution of the lozenge in the mouth, have been described and compared with nicotinepolacrilex gum also using a polacrilex resin [16]. The efficacy of the Nicotinell lozenges studied in this review has previously been described $[17,18]$. The versatility of lozenges has also been demonstrated in the treatment of smokers who had previously failed to quit on other NRT products, and of both very heavy and moderate/light smokers [19-21]. Indeed, when compared to the gum, lozenges are characterized by a number of advantages, such as fewer potential oral health limitations (e.g. dental works or temporomandibular joint pain), better social acceptance (e.g. at workplaces), and greater ease of use as they do not require chewing. As opposed to patches, lozenges provide all the advantages of acute dosage forms described above [22], including the possibility of selfadaptation of the dose and some degree of behavioral activity and sensory stimulation, which might be crucial for smokers trying to quit.

Despite considerable literature, there are few published studies directly comparing different NRT products [9]. In addition, pharmacokinetic (PK) data on nicotine lozenges in the literature remain scarce [23]. The present review provides the first comprehensive description of the PK profiles of 1 and $2 \mathrm{mg}$ Nicotinell lozenges in comparison with 2 and $4 \mathrm{mg}$ nicotine gum. In addition, the efficacy and safety of the $1 \mathrm{mg}$ Nicotinell lozenge in smoking cessation are documented.

\section{Methods \\ General}

All presented studies were carried out in compliance with the Helsinki Declaration and its amendments and Good Clinical Practices. All protocols were accepted by local ethics committees (Table 1). All subjects provided written informed consent before enrolment in the studies.

Participants to the studies were adult, healthy smokers usually smoking at least 20 cigarettes per day in the PK trials, or at least 10 cigarettes per day in the safety trial. Dur-

Table I: Ethic committee approvals

Study
- single-dose, comparing I and 2 mg lozenges with 2 mg gum
- multiple-dose, comparing I mg lozenge with 2 mg gum
- multiple-dose, comparing I and 2 mg lozenges with 4 mg gum
- safety assessment of I mg lozenge after swallowing
- French efficacy trial
- US efficacy trial

Ethical Committee

CCPPRB de Franche-Comté, France

CCPPRB of the Hôtel-Dieu Hospital (Lyon - France)

CREC Regipharm (Brussels - Belgium)

CCPPRB of the Pitié-Salpêtrière Hospital (Paris - France)

IRB at Research Testing Laboratories, Inc. (Great Neck, NY, USA) 
ing the PK and safety trials, participants were maintained under highly controlled conditions, including standardized food and fluid intake, restricted physical activity, and cigarette abstinence. Non-smoking compliance was controlled by measurement of carbon monoxide (CO) in expired air. Blood samples were collected at planned timepoints. Concentrations of nicotine and cotinine in plasma or urine were determined by validated GC-MS methods with limits of quantification at respectively $1 \mathrm{ng} / \mathrm{ml}$ and $10 \mathrm{ng} / \mathrm{ml}$ for nicotine and cotinine (LC-MS/MS for the multiple-dose study comparing 1 and 2 mg lozenges with $4 \mathrm{mg}$ gum). Residual nicotine content in the chewed gum (or sucked lozenge) after use was determined by HPLC.

\section{Single-dose pilot study comparing I and 2 mg lozenges with 2 mg gum}

This was a single-center, open-label, single-dose, randomized, three-way, crossover pilot study in nine male volunteers to assess the PK parameters of $1 \mathrm{mg}$ Nicotinell lozenges (containing $3.07 \mathrm{mg}$ nicotine bitartrate dihydrate equivalent to $1 \mathrm{mg}$ nicotine base), $2 \mathrm{mg}$ Nicotinell lozenges (containing $6.134 \mathrm{mg}$ nicotine bitartrate dihydrate equivalent to $2 \mathrm{mg}$ nicotine base), and $2 \mathrm{mg}$ nicotine gum (Nicorette ${ }^{\circledast}$ gum; Pharmacia A.B.; containing $10 \mathrm{mg}$ nicotine carboxylate cation resin equivalent to $2 \mathrm{mg}$ nicotine base). The same brand of comparator gum was used throughout the ensuing clinical development. Subjects were randomized to one of the three groups and received one piece of trial medication during each of the three 32hour observation periods, which always started with a 24hour non-smoking phase, and were separated by 7-day washouts. Lozenges were sucked and gum chewed for 30 min according to a controlled schedule, and remainders were collected to measure drug delivery. In this pilot study, lozenges were not completely dissolved at the end of $30 \mathrm{~min}$, therefore the sucking pattern was modified for subsequent studies. Blood was drawn before dosing and at $15,30,45 \mathrm{~min}, 1,1.25,1.5,2,3,4,6$, and $8 \mathrm{~h}$ after dosing. Urine was collected during the $24 \mathrm{~h}$ run-in preceding administration and between $0-4 \mathrm{~h}$ and $4-8 \mathrm{~h}$ after dosing. Main criteria for comparison between different drugs were $\mathrm{AUC}_{0-\infty}$ and $\mathrm{C}_{\max }$ which were corrected for $100 \%$ drug delivery from lozenge. Ln-transformed values were submitted to 4-factor ANOVA (sequence, subject, period, treatment).

\section{Multiple-dose study comparing I mg lozenge with 2 mg gum}

This was a single-center, open-label, multiple-dose, randomized, two-way, crossover PK study in 24 male volunteers that compared $1 \mathrm{mg}$ Nicotinell lozenges with $2 \mathrm{mg}$ nicotine polacrilex gum. Two 2-day observation periods were separated by a 7-day washout and each period started with a 22-hour run-in phase without smoking, followed by a 12-hour dosing phase and a 23-hour sampling phase. Twelve doses of nicotine were administered, i.e. one per hour from $t=0$ to $t=11$. Lozenges were sucked until complete dissolution, and the time needed to achieve this (usually about $30 \mathrm{~min}$ ) was reported. Gum was chewed for $30 \mathrm{~min}$ according to a schedule monitored by a computer-controlled beeper, and residues were collected and frozen for HPLC analysis. Blood was drawn pre-dose, 15, 30 and $45 \mathrm{~min}$ after the first dose. In addition, blood was drawn before each new dose (at 1, 2, 3, 4, $5,6,7,8,9,10$, and $11 \mathrm{~h}$ ) and after the last dose at 11.25, $11.5,11.75,12,12.25,12.5,13,13.5,14,15,17,19,21$, and $23 \mathrm{~h}$ (all times after first dose).

Main criteria for comparison of nicotine PK at steady state were $\mathrm{C}_{\max } \mathrm{t}_{\max }$ and $\mathrm{AUC}_{11-12}$ (AUC during one dosing interval). Secondary criteria were first dose data $\left(\mathrm{C}_{\max }\right.$ $\left.t_{\max ^{\prime}} A C_{0-1}\right), C_{\text {min }}$ before each dose and $t_{1 / 2}$ after the last dose. In addition, urinary and saliva $\mathrm{pH}$ variations were assessed and safety was controlled through assessment of cardiovascular parameters (blood pressure (BP), heart rate (HR), and ECG), standard laboratory tests and incidence of adverse events (AEs). $\mathrm{C}_{\max }$ and $\mathrm{AUC}_{11-12}$, ln-transformed values were submitted to 4-factor ANOVA (sequence, subject, period, treatment). A $90 \%$ confidence interval (CI) was constructed for the ratio (e.g. for lozenge/gum) of $\mathrm{C}_{\max }$ and $\mathrm{AUC}_{11-12}$ respectively. The primary criterion for relative bioequivalence was that the $90 \%$ confidence limits fall within the interval [0.80$1.25]$, i.e. the standard bioequivalence acceptance range (BAR). When appropriate, the enlarged BAR [0.7-1.43] was applied.

\section{Multiple-dose study comparing I and 2 mg lozenges with 4 mg gum}

This was a single-center, open-label, multiple-dose, randomized, three-way, crossover PK study in 31 male volunteers. Its primary objectives were: (1) to confirm the doseconcentration proportionality between Nicotinell 1 and 2 mg lozenges and (2) to compare nicotine systemic exposure by Nicotinell $2 \mathrm{mg}$ lozenge with that of Nicorette 4 mg gum. Secondary objectives were the completion of the PK profile of the $2 \mathrm{mg}$ Nicotinell lozenge and the comparison of clinical safety of the three nicotine formulations. There were three treatment periods of $12 \mathrm{~h}$ (one for each product), separated by 7 -day washout periods. Smoking was prohibited during the $24 \mathrm{~h}$ preceding treatment and until leaving the study center. During each treatment period, a total of twelve doses of nicotine were administered at a rate of 1 dose per hour. Lozenges were sucked until complete dissolution and gum were chewed for 30 min at 60 chews/min (timed using a calibrated metronome) while the subjects remained in a seated position. Blood samples for determination of plasma nicotine and cotinine concentrations were drawn pre-dose and at 7 and $9 \mathrm{~h}$. After intake of the last dose ( $11 \mathrm{~h})$, blood was drawn 
at $11.25,11.5,11.75,12.5,13,14,15,17,19,21$, and 23 h. Tolerability was assessed by spontaneous reporting of AEs.

Primary PK parameters for evaluation were steady state data after the last dose $\left(\mathrm{AUC}_{11-12}, \mathrm{C}_{\max }\right.$ and $\mathrm{t}_{\max }$ ). For the comparison between 1 and $2 \mathrm{mg}$ lozenges (dose proportionality) and between $2 \mathrm{mg}$ lozenge and $4 \mathrm{mg}$ gum, lntransformed values for $\mathrm{C}_{\max }$ and $\mathrm{AUC}_{1112}$ were submitted to 4-factor ANOVA (sequence, subject, period, treatment). Relative bioequivalence was determined by construction of $90 \%$ CIs and application of the standard BAR [0.801.25] and enlarged BAR [0.7-1.43] for the ratios of $C_{\max }$ and $\mathrm{AUC}_{11-12}$, and by Friedman ANOVA for $\mathrm{t}_{\text {max }}$. In addition, complete safety and tolerability data were collected, including physical examination and vital signs, cardiovascular parameters, standard laboratory tests and incidence of AEs.

\section{Safety of I mg lozenge after swallowing}

This was a single-center, open-label, escalating-dose, sequential group safety study with 24 volunteers of both sexes. The participants were divided into three groups of eight: subjects in group A swallowed three lozenges, in group B six lozenges, and in group C 12 lozenges. For every group, subjects were included in two steps: first, two volunteers were assessed, and if the administered dose was well tolerated the other six volunteers were included. Each dose level was followed by a 2-day observation period, including a $12 \mathrm{~h}$ period after dosing during which smoking was prohibited. Lozenges were swallowed as a single dose with $250 \mathrm{ml}$ of water. Safety was assessed by examination of the plasma nicotine levels, subjects' clinical status, standard laboratory testing, gastric motility test (only the first two subjects of each group) and AEs reporting. Blood for determination of plasma nicotine levels was drawn pre-dose and 10, 20, 30, 40, $50 \mathrm{~min}, 1,1.5,2$, $2.5,3,3.5,4,5,6,7,8,9,10,11,13,16$ and 48 h postdose.

Criteria for safety evaluation were as follows: (1) $\mathrm{C}_{\max }$ and $\mathrm{t}_{\max }$ after each dose, as well as $\mathrm{AUC}_{10 \text { min-12 } \mathrm{h}}$ for nicotine PK; (2) BP, HR, ECG, and physical examination for clinical status; (3) hematology, biochemistry (including hepatic parameters, serology and urinalysis), carboxyhemoglobin, carcinoembryonic antigen, and urinary cotinine and catecholamine levels for laboratory testing; and (4) gastric emptying and antral motor activity for gastric motility. Nicotine PK parameters were analyzed by summary statistics of all nicotine concentrations, AUC, $t_{\text {max }}$ $\mathrm{C}_{\text {max }}$ and comparison of PK values by one-way ANOVA. BP and HR were analyzed by an ANOVA GLM model for systolic and diastolic values, as well as for the difference (systolic - diastolic); factors for ANOVA were subject, period and treatment. All other parameters were analyzed within each treatment group by Wilcoxon paired test (prevs. post-dosing). Post-entry differences of each treatment group were compared by one-way ANOVA or KruskalWallis test, as appropriate. For all parameters, McNemar test was used to detect volunteers who changed their status from entry to post-dosing in terms of normal range limits.

\section{Efficacy trials with I mg lozenge}

Two large phase 3 studies were performed to assess the efficacy of $1 \mathrm{mg}$ Nicotinell lozenge in smoking cessation, one in France (37 centers; AFSSAPS trial registration number: 980324) and one in the USA (3 centers; registration number 905.1295). The 2 trials had a double-blind, placebo-controlled, randomized, parallel groups design. The patients, respectively for the French and the American trials, were distributed as follows: (1) randomized and received at least one treatment: 436 and 460 patients, (2) received active lozenge: 214 and 230 patients, (3) received placebo lozenges: 222 and 230 subjects. Eligible subjects were healthy smokers of both sexes and aged $\geq 18$ years, motivated to quit. To have a global view on the lozenge efficacy over a wide range of dependence levels, patients had either a medium to high dependence of smoking in the French study (Fagerström Test for Nicotine Dependence (FTND) [24] score of 4-7 and smoking 10-30 cigarettes/day), or a high to very high dependence in the US study (FTND score $\geq 6$ and smoking 20-40 cigarettes/ day). Subjects were advised to suck between 8 and 25 lozenges each day (dosage self-adjusted by subjects) for six weeks, followed by complete weaning over the next six weeks with a suggested decrease of one lozenge per day relative to the dose at week 6 . Subjects attended the study site at screening (baseline), biweekly or weekly up to week 6 , and then at week 12 , and 26 . After week 6 , only abstinent subjects were continuously followed-up. At visits, smoking status (exhaled-breath CO), BP, HR, weight, and AEs were recorded. From weeks 0-6 (France) or 0-12 (USA), subjects recorded daily in a diary the number of lozenges used and of cigarettes smoked (if any), plus any withdrawal symptoms experienced. During the study no formal behavioral counseling was offered to patients. The primary efficacy outcome measure was the proportion of patients continuously and completely abstinent (no cigarettes and $\mathrm{CO}<10 \mathrm{ppm}$ ) during the four weeks preceding week 6 and the number of subjects to include was calculated according to this objective. Secondary efficacy outcomes were the point prevalence abstinence rates at the visits on week 12 and on week 26, the evolution of withdrawal symptom scores, and partial abstinence rates (partial abstinence defined as smoking of $\leq 1$ cigarette per day and $\leq 7$ cigarettes per week, and $\mathrm{CO}<10 \mathrm{ppm}$ ) on week 6 , 12 and 26. Safety of treatment (AEs, BP, HR, weight) and levels of urine nicotine metabolites (French study only) were further outcome measures. Efficacy was analyzed 
using Cochran-Mantel-Haenszel statistic, stratified by study center. Comparison between treatments was made using the Cochran-Mantel-Haenszel chi-square test, after adjusting for pooled centers. The experimental details and results of the French trial have previously been described $[17,18]$.

\section{Results \\ Single dose pilot study: PK comparison of I and $2 \mathrm{mg}$ lozenges with 2 mg gum}

Key PK results are summarized in Table 2. The sucking pattern in this trial did not result in full dissolution of the lozenges and only approximately $67 \%$ of their nicotine content was released. Thus, a correction was applied to calculate $\mathrm{C}_{\max }$ and $\mathrm{AUC}_{0-\infty}$ for a fully dissolved lozenge. This was deemed appropriate because lozenges are designed to be fully sucked out by users. The adjusted values for $\mathrm{C}_{\max }$ and $\mathrm{AUC}_{0-\infty}$ of $1 \mathrm{mg}$ lozenge and $2 \mathrm{mg}$ gum were similar and thus indicated comparable nicotine delivery from these two formulations. In addition, comparison of PK parameters of 1 and 2 mg lozenges demonstrated dose-concentration proportionality between these doses, which was verified in an ensuing multiple-dose study (see below).

During metabolization, nicotine is converted into several metabolites including cotinine, which are finally excreted in urine. Further support for comparable PK properties of $1 \mathrm{mg}$ lozenge and $2 \mathrm{mg}$ gum came from mean plasma cotinine kinetics, including $\mathrm{C}_{\max }(19.9 \rightarrow$ adjusted 29.7 $\mathrm{ng} / \mathrm{ml}$ with lozenge vs. $30.2 \mathrm{ng} / \mathrm{ml}$ with gum), $\mathrm{AUC}_{0-\mathrm{t}}$ $\left(102 \rightarrow 152\right.$ h.ng/ml vs. 153 h.ng/ml), $t_{\max }(5.2$ vs. 5.3 h), and $t_{1 / 2}(9.4$ vs. $11.4 \mathrm{~h})$. Similarly, urinary cotinine values were comparable between $1 \mathrm{mg}$ lozenge and $2 \mathrm{mg}$ gum, and dose-concentration relationship was apparent for urinary cotinine excretion after dosing with $1 \mathrm{mg}$ vs. $2 \mathrm{mg}$ lozenges (data not shown). Among the 18 AEs observed, only 2 were considered to be related to study drug (throat irritation with $2 \mathrm{mg}$ lozenge and gum), but none was serious. No other clinically relevant abnormalities were noted with any of the products.

\section{Bioequivalence of I $\mathbf{~ m g ~ l o z e n g e ~ a n d ~} 2 \mathrm{mg}$ gum at steady state}

As the pilot study suggested bioequivalence of $1 \mathrm{mg} \mathrm{loz}$ enges and $2 \mathrm{mg}$ gum, this trial was designed to confirm this bioequivalence between these two formulations, focusing on PK characteristics after multiple doses and at steady state. Median duration for complete dissolution of lozenges over the entire study period was $29.25 \mathrm{~min}$ (range 27-31 $\mathrm{min}$ ). The mean amount of nicotine extracted from the gum increased from $1.0 \mathrm{mg}$ at dose 1 to $1.13 \mathrm{mg}$ at dose $12(+13 \%)$. Therefore, an adjustment was applied to the amount of nicotine actually delivered by gum at different time-points in order to ensure consistent statistical analysis of PK parameters. Both NRT products led to an increase in saliva $\mathrm{pH}$ after dosing, the lozenge having a significantly higher buffering power than the gum (data not shown), which is known to favor a nonionized state of nicotine and its absorption [25,26]. As expected, median $\mathrm{t}_{\max }(0.76$ vs. $0.75 \mathrm{~h})$, mean $\mathrm{C}_{\max }(4.2 \pm$ 1.8 vs. $5.0 \pm 1.6 \mathrm{ng} / \mathrm{ml})$ and $\mathrm{AUC}_{0-1}(2.9 \pm 1.4$ vs. $3.5 \pm 1.3$ h.ng/ml) were similar for lozenge and gum after the first dose $(0-1 \mathrm{~h})$.

Plotting of plasma nicotine concentrations over time after repeated administration of Nicotinell $1 \mathrm{mg}$ lozenges and $2 \mathrm{mg}$ polacrilex gum revealed that the plateau of concentration was reached after intake of six doses (Figure 1).

The blood draws after the last dose allowed to determine PK characteristics at steady state. The observed kinetics

Table 2: PK parameters of nicotine in plasma after intake of a single dose of lozenge or gum (mean \pm SD; $n=9)$

\begin{tabular}{|c|c|c|c|}
\hline \multirow[t]{2}{*}{ FormulationIPK parameter } & \multicolumn{2}{|c|}{$\begin{array}{l}\text { Nicotinell } \\
\text { lozenge }\end{array}$} & \multirow{2}{*}{$\begin{array}{c}\begin{array}{c}\text { Nicorette } \\
\text { gum }\end{array} \\
2 \mathrm{mg}\end{array}$} \\
\hline & I mg & $2 \mathrm{mg}$ & \\
\hline $\begin{array}{l}\text { Amount of nicotine released after } \mathbf{3 0} \text { min ( } \mathbf{m g}) \\
{[\% \text { of minimal content }]}\end{array}$ & $\begin{array}{l}0.67 \pm 0.14 \\
\quad[67 \%]\end{array}$ & $\begin{array}{l}1.39 \pm 0.28 \\
\quad[67 \%]\end{array}$ & $\begin{array}{l}0.81 \pm 0.25 \\
\quad[42 \%]\end{array}$ \\
\hline $\begin{array}{l}\text { observed } \mathbf{C}_{\max }(\mathbf{n g} / \mathbf{m l}) \\
\text { [adjusted] } t \ddagger\end{array}$ & $\begin{array}{l}2.3 \pm 0.8 \\
{[3.5 \pm 1.1]^{\dagger}}\end{array}$ & $\begin{array}{l}4.8 \pm 1.4 \\
{[7.0 \pm 1.7]}\end{array}$ & $2.9 \pm 1.2$ \\
\hline $\mathbf{t}_{\text {max }}(\mathbf{h})$ & $\begin{array}{c}\mathrm{I} . \mathrm{I} \pm 0.7 \\
{[0.8(0.8-3.0)]}\end{array}$ & $\begin{array}{c}0.8 \pm 0.2 \\
{[0.8(0.6-1.1)]}\end{array}$ & $\begin{array}{c}0.8 \pm 0.1 \\
{[0.8(0.5-1.0)]}\end{array}$ \\
\hline$t_{1 / 2}(h)$ & $2.7 \pm 0.7$ & $2.8 \pm 0.7$ & $2.5 \pm 1.0$ \\
\hline $\mathrm{AUC}_{0-\mathrm{t}}(\mathrm{h} \cdot \mathrm{ng} / \mathrm{ml})$ & $8.3 \pm 2.5$ & $15.8 \pm 4.1$ & $10.6 \pm 4.4$ \\
\hline $\begin{array}{l}\text { observed } \mathbf{A U C} \mathbf{C}_{\mathbf{0}}(\mathbf{h} \cdot \mathbf{n g} / \mathbf{m l}) \\
\text { [adjusted] }{ }^{\dagger \ddagger}\end{array}$ & $\begin{array}{l}10.7 \pm 3.1 \\
{[16.5 \pm 4.6]}\end{array}$ & $\begin{aligned} 20.0 & \pm 5.9 \\
{[30.1} & \pm 9.7]\end{aligned}$ & $13.8 \pm 5.6$ \\
\hline
\end{tabular}

$t$ : Since in this trial nicotine lozenges were not completely dissolved after 30 min of sucking, an adjustment was made for nicotine delivery by a full I mg dose.

†: Adjustment for nicotine delivery by a full $2 \mathrm{mg}$ dose. 


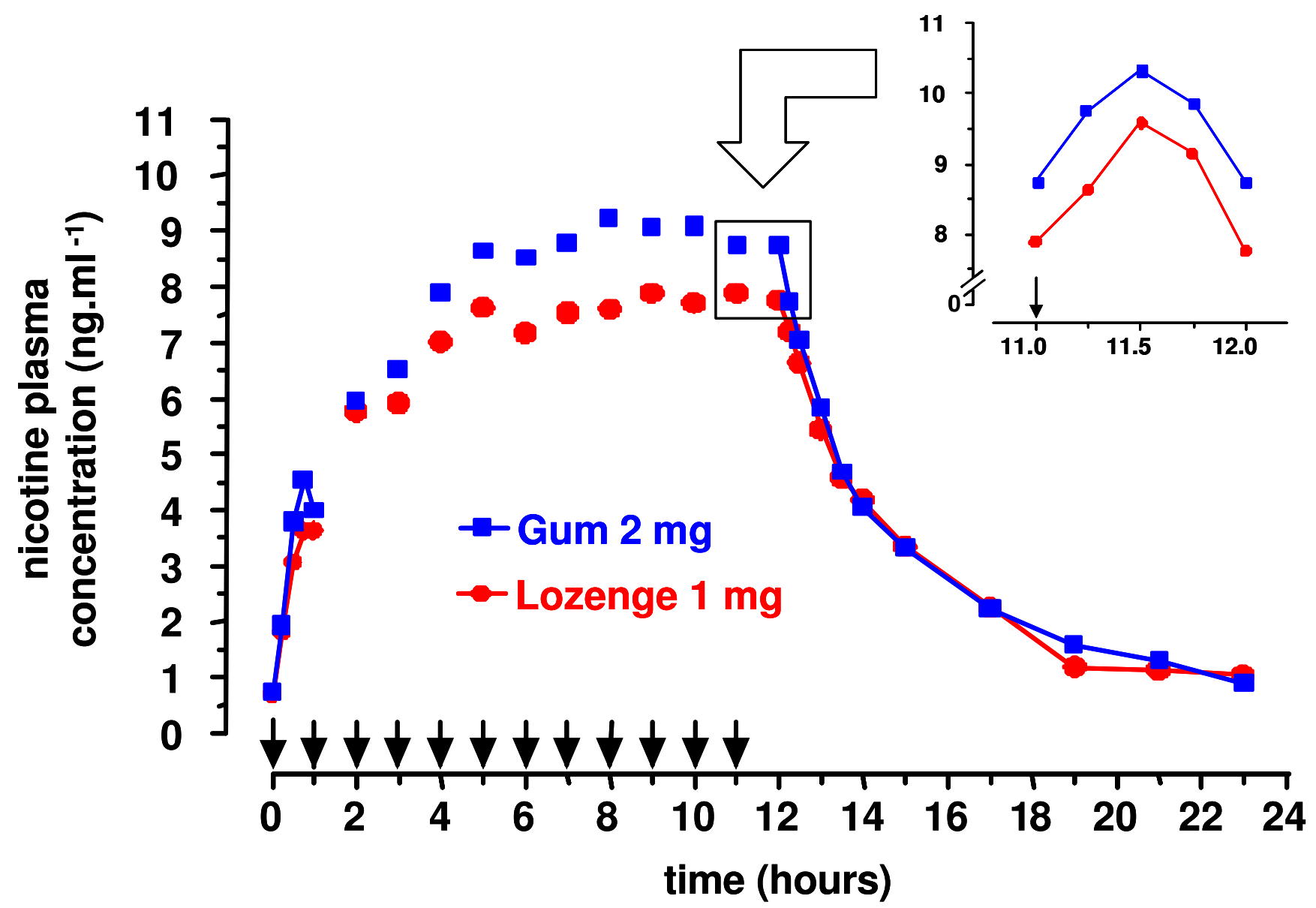

Figure I

Nicotine plasma concentration after repeated intake ( 24 subjects). Nicotine plasma concentrations were determined in this multiple-dose bioequivalence trial with 24 volunteers from blood samples drawn before administration of each single dose (unconnected data points). Consecutive blood samples (connected data points) were drawn after administration of dose $\mathrm{I}(\mathrm{t}=0)$ and dose $\mathrm{I} 2(\mathrm{t}=\mathrm{II} \mathrm{h})$. The insert shows a blood nicotine peak after dosing at steady state obtained with blood draws after dose $12(\mathrm{II}-\mathrm{I} 2 \mathrm{~h})$.

suggested that intake of lozenges or gum under these conditions lead to "peak-trough" kinetics of nicotine similar to those observed during day-time in dependent smokers having cigarettes, but much reduced in intensity. Indeed, the highest concentration (approximately $11 \mathrm{ng} / \mathrm{ml}$ ) obtained with the tested formulations corresponds to the lower end of the range of blood nicotine levels (10-50 ng/ $\mathrm{ml}$ ) observed in smokers in the afternoon (i.e. at steady state) $[14]$.

The determined values for $\mathrm{C}_{\text {max }^{\prime}} t_{\max }$ and $\mathrm{AUC}_{11-12}$ showed that nicotine delivery characteristics of $1 \mathrm{mg}$ Nicotinell lozenge and $2 \mathrm{mg}$ polacrilex gum at steady state were comparable (Table 3 ). When bioequivalence was statistically assessed, the $90 \%$ CIs for $\mathrm{C}_{\max }$ and $\mathrm{AUC}_{11-12}$ remained within the standard BAR [0.80-1.25], indicat- ing bioequivalence of the $1 \mathrm{mg}$ lozenge and the $2 \mathrm{mg}$ gum under the studied conditions. When unadjusted values for gum were considered, the $90 \%$ CIs for $\mathrm{C}_{\max }$ and $\mathrm{AUC}_{11-12}$ of lozenge (0.76-0.93 and $0.75-0.91$, respectively) still fell within the enlarged BAR [0.7-1.43], which may be considered acceptable for oral nicotine, due to its broad therapeutic range and self-titration behavior of users [2729].

With respect to safety, 12 volunteers had a total of 40 AEs, which were all mild to moderate, with complete recovery. Six AEs ( 2 for lozenge and 4 for gum) were considered as drug-related: headache, salivation, hiccups, flatulence and throat irritation. No other clinically relevant abnormalities were observed, neither for cardiovascular parameters, nor for laboratory testing. 
Table 3: PK parameters of nicotine in plasma at steady state after 12 hourly dosest of I $\mathrm{mg}$ lozenge or $2 \mathrm{mg}$ gum (mean \pm SD; $\mathrm{n}=\mathbf{2 4}$ )

\begin{tabular}{|c|c|c|c|}
\hline \multirow[t]{2}{*}{ FormulationIPK parameter } & Nicotinell ${ }^{\circledR}$ lozenge & Nicorette ${ }^{\circledR}$ gum & \multirow[t]{2}{*}{$90 \% \mathrm{Cl}$ (lozenge/gum) } \\
\hline & I mg & $2 \mathbf{m g} \ddagger$ & \\
\hline$C_{\max }(\mathrm{ng} / \mathrm{ml})$ & $10.6 \pm 2.9$ & $11.4 \pm 3.8$ & $0.86-1.04$ \\
\hline$C_{\min }(\mathrm{ng} / \mathrm{ml})$ & $8.1 \pm 2.4$ & $9.3 \pm 3.4$ & ND \\
\hline$t_{\max }(h)$ [range] & $0.54 \pm 0.21[0.00-0.77]$ & $0.47 \pm 0.19[0.20-0.95]$ & ND \\
\hline$t_{1 / 2}(h)$ & $3.6 \pm 1.2$ & $3.2 \pm 0.9$ & ND \\
\hline$A U C_{11-12}(h \cdot n g / m l)$ & $9.2 \pm 2.6$ & $10.2 \pm 3.4$ & $0.84-1.01$ \\
\hline
\end{tabular}

Initial nicotine concentrations in plasma were $1.1 \mathrm{ng} / \mathrm{ml}$ (range: $0.0-6.5)$ with lozenge and $0.9 \mathrm{ng} / \mathrm{ml}(0.0-5 . \mathrm{I})$ with gum, reflecting volunteers' heavy smoking habits ( $\geq 20$ cigarettes per day). Correction for initial nicotine concentrations did not modify the results and thus was not retained. ND: not determined.

t: PK parameters were determined from blood samples drawn after dose $12(\mathrm{t}=1 \mathrm{I} \mathrm{h})$ until $\mathrm{t}=23 \mathrm{~h}$.

\#: a dose adjustment of the raw data was done for a last standard dose of I mg nicotine delivery from the gum.

\#: Standard $90 \% \mathrm{Cl}$ for the expected mean ratio was derived from ANOVA for continuous parameters and compared to standard BAR [0.80-I.25]

Dose proportionality between I and $2 \mathrm{mg}$ lozenges and comparison with $4 \mathbf{~ m g}$ gum at steady state

This study was performed to confirm the dose-concentration proportionality between 1 and $2 \mathrm{mg}$ Nicotinell lozenges, and to compare the nicotine PK profile of lozenges with that of $4 \mathrm{mg}$ nicotine gum. Overall trial design was comparable to the previous multiple-dose study, with intake of 12 doses of nicotine by 31 volunteers ( 1 dose per hour, 30 min of sucking or standardized chewing) and assessment of plasma nicotine PK parameters at steady state (successive blood draws after dose 12). Thirteen out of $31(42 \%)$ of all trial participants had significant baseline plasma nicotine levels on two or three periods, but no differences were observed between the three treatment groups. Thus, these baseline levels were not taken into account, as they did not influence the comparison between groups. The plateau concentration for plasma nicotine was reached before the 12 th dose. With respect to dose-concentration proportionality between the 1 and 2 mg lozenge, an adjustment for the same dose $(2 \mathrm{mg})$ was applied, and $\mathrm{C}_{\max }$ and $\mathrm{AUC}_{11-12}$ were determined (Table 4). As expected, the $90 \%$ CIs of the ratio of $\mathrm{C}_{\max }$ and $\mathrm{AUC}_{11-12}$ fell within the standard BAR [0.80-1.25], thus demonstrating a linear dose-concentration relationship between the two strengths of nicotine lozenge (Figure 2). In addition, $\mathrm{t}_{\max }$ did not to differ significantly (Friedman ANOVA).

As bioequivalence between $1 \mathrm{mg}$ lozenges and $2 \mathrm{mg}$ gum had been shown (see above) and as 1 and $2 \mathrm{mg}$ lozenges showed dose proportionality, one of the aims of this study was to compare $2 \mathrm{mg}$ lozenge with $4 \mathrm{mg}$ gum. With $2 \mathrm{mg}$ lozenges, $\mathrm{C}_{\max }$ and $\mathrm{AUC}_{11-12}$ were approximately $26 \%$ lower than with $4 \mathrm{mg}$ gum. No bioequivalence was observed (Table 5, Figure 3).

Analysis of safety and tolerability was considered of particular value in this trial, as participants were treated with a wide range of nicotine doses under consistent conditions. Overall, no significant variations were reported in physical examination, vital signs, cardiovascular parameters or clinical laboratory tests. There were no serious or unexpected AEs. One subject was withdrawn due to vomiting when taking the $2 \mathrm{mg}$ lozenges. The relationship was considered probable. Sixteen subjects reported a total of 29 AEs during the entire trial, which were all mild to mod-

Table 4: Steady statet plasma nicotine PK parameters after intake of I or $\mathbf{2} \mathbf{~ m g}$ lozenges to determine dose-concentration proportionality (mean \pm SD; $n=3 I$ )

\begin{tabular}{|c|c|c|c|c|}
\hline \multirow{2}{*}{$\begin{array}{l}\text { FormulationIPK } \\
\text { parameter }\end{array}$} & \multicolumn{2}{|c|}{ Nicotinell ${ }^{\circledR}$ lozenge I mg } & \multirow{2}{*}{$\begin{array}{c}\text { Nicotinell }^{\circledR} \text { lozenge } \\
2 \mathrm{mg}\end{array}$} & \multirow[t]{2}{*}{$90 \% \mathrm{Cl}(2 \mathrm{mg} / \mathrm{l} \mathrm{mg})^{\#}$} \\
\hline & observed & adj. to 2 mg $\ddagger$ & & \\
\hline$C_{\max }(\mathrm{ng} / \mathrm{ml})$ & $11.0 \pm 4.9$ & $22.0 \pm 9.8$ & $22.5 \pm 7.0$ & $0.97-1.19(\mathrm{~F}=1.07)$ \\
\hline $\mathbf{t}_{\max }$ (h) Median [range] & $0.5[0.25-1.00]$ & - & $0.5[0.25-1.02]$ & NS (Friedman ANOVA) \\
\hline$A_{1 /-12}(\mathrm{~h} \cdot \mathrm{ng} / \mathrm{ml})$ & $9.7 \pm 3.9$ & $19.3 \pm 7.8$ & $20.2 \pm 6.8$ & $0.98-1.20(F=1.08)$ \\
\hline
\end{tabular}

NS: not significant.

$t:$ PK parameters were determined from blood samples drawn after dose $12(\mathrm{t}=\mathrm{Il} \mathrm{h})$ until $\mathrm{t}=23 \mathrm{~h}$.

¥: Experimental values (plasma nicotine concentrations) observed with I $\mathrm{mg}$ lozenge were adjusted to a hypothetical 2 mg dose before calculation of PK parameters.

\#: Standard $90 \% \mathrm{Cl}$ for the expected mean ratio was derived from ANOVA for continuous parameters and compared to standard BAR [0.80-I.25].

F: relative bioavailability ratio. 


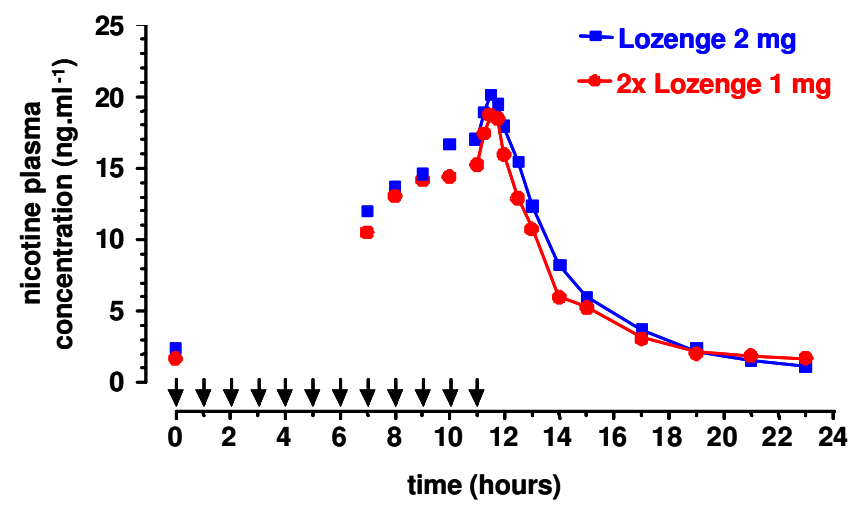

Figure 2

Dose proportionality of nicotine lozenges with respect to nicotine plasma concentrations ( 3 I subjects). Nicotine plasma concentrations were determined from blood samples of 31 volunteers drawn before hourly administration I or $2 \mathrm{mg}$ nicotine lozenge (unconnected data points). Consecutive blood samples (connected data points) were drawn after administration of dose $12(\mathrm{t}=\mathrm{II} \mathrm{h})$, and the derived data points are connected. Plasma concentrations obtained with I mg lozenges were doubled for ease of comparison.

erate. The most frequent AEs assessed as at least possibly related to treatments were: hiccup (reported by 10 subjects, nine of which under the gum), throat irritation (two times with 2 mg lozenges and three times with gum), and nausea (ditto). Globally, more AEs were reported with the $4 \mathrm{mg}$ gum than with the 1 or $2 \mathrm{mg}$ lozenges, suggesting overall good tolerability of the latter formulation.

\section{Safety in case of misuse of I mg lozenges}

All clinical assessments performed in the PK trials, as well as reported AEs, suggested a favorable safety profile for Nicotinell ${ }^{\circledast}$ lozenges. However, in these trials one lozenge at a time was administered and subjects were sucking them slowly without concomitantly smoking. Yet, nicotine from oral formulations is not only taken up via the oral mucosa, but is also partially absorbed from the gastrointestinal tract [26]. To assess the safety in case of swallowing large quantities of $1 \mathrm{mg}$ lozenges, an escalatingdose safety open study was performed: three groups (A, B, $\mathrm{C})$, each including eight male or female subjects who were at least moderate smokers ( $\geq 10$ cigarettes/day) received either 3, 6, or 12 Nicotinell $1 \mathrm{mg}$ lozenges, to be swallowed at once with water. Smoking abstinence prior to dosing was not asked for and all of the volunteers (except one) had measurable levels of nicotine in plasma before lozenge intake. Blood was drawn until $48 \mathrm{~h}$ post-dose and plasma nicotine PK parameters were determined (Table $6)$. The highest mean concentration observed $(20.5 \pm 8.8$ $\mathrm{ng} / \mathrm{ml}$ ) under these experimental conditions of misuse still fell largely within the range of plasma nicotine concentrations observed in active cigarette smokers (10-50 $\mathrm{ng} / \mathrm{ml}$ ) [14]. Of note, these observed concentrations were not corrected for the considerable baseline nicotine levels of the subjects.

The safety of lozenges when misused was also monitored through the assessment of the clinical status (including cardiovascular parameters), laboratory test results and occurrence of AEs. The different extents (according to dose) of nicotine absorption were not reflected in BP, HR, and ECG values, nor were any clinically significant changes in cardiac or laboratory parameters observed. No serious AEs were reported. Only one minor AE occurred in groups A and B (headache during $1 \mathrm{~h}$ ). In group C, six volunteers reported transient stomach heaviness lasting for up to $1 \mathrm{~h}$ after ingestion of the 12 lozenges. Gastric antral motor activity determined at 1 and $11 \mathrm{~h}$ post-dosing was identical to normal physiological values $(3 \pm 0.5$ cycles/ $\min )$. Gastric half clearance times at 1 and $11 \mathrm{~h}$ post-dosing were within the standard range ( $55 \pm 15 \mathrm{~min}$ ) for subjects receiving 3 or 6 lozenges, but not for those receiving 12 lozenges; the latter complained about stomach heaviness at $1 \mathrm{~h}$ post-dosing and displayed shortened gastric half clearance times ( 26 and $34 \mathrm{~min}$ ). However, these AEs resolved spontaneously, and clearance half-times at $11 \mathrm{~h}$ post-dosing were again well within the standard range (49 and $62 \mathrm{~min}$ ).

Table 5: PK parameters of nicotine in plasma at steady state after 12 hourly dosest of $2 \mathrm{mg}$ lozenge or $4 \mathrm{mg}$ gum (mean \pm SD; $\mathrm{n}=3 \mathrm{I}$ )

\begin{tabular}{|c|c|c|c|}
\hline \multirow[t]{2}{*}{ FormulationIPK parameter } & \multirow{2}{*}{$\begin{array}{c}\text { Nicotinell }^{\circledR} \text { lozenge } \\
2 \mathrm{mg}\end{array}$} & \multirow{2}{*}{$\begin{array}{c}\text { Nicorette }^{\circledR} \text { gum } \\
4 \mathrm{mg}\end{array}$} & \multirow[t]{2}{*}{ 90\% Cl (lozenge/gum) $\ddagger$} \\
\hline & & & \\
\hline$C_{\max }(\mathrm{ng} / \mathrm{ml})$ & $22.5 \pm 7.0$ & $30.5 \pm 12.8$ & $0.69-0.89(F=0.78)$ \\
\hline $\mathbf{t}_{\max }(\mathrm{h})$ Median [range] & $0.5[0.25-1.02]$ & $0.5[0.25-1.00]$ & NS (Friedman ANOVA) \\
\hline$A C_{1 /-12}(h \cdot n g / m l)$ & $20.2 \pm 6.8$ & $27.5 \pm 11.4$ & $0.68-0.88(F=0.77)$ \\
\hline
\end{tabular}

NS: not significant.

†: PK parameters were determined from blood samples drawn after dose $12(\mathrm{t}=11 \mathrm{~h})$ until $\mathrm{t}=23 \mathrm{~h}$.

\#: Standard $90 \% \mathrm{Cl}$ for the expected mean ratio (test/reference $=$ lozenge/gum) was derived from ANOVA for continuous parameters and

compared to standard BAR [0.80-1.25] and enlarged BAR [0.7-1.43]. F: relative bioavailability ratio. 


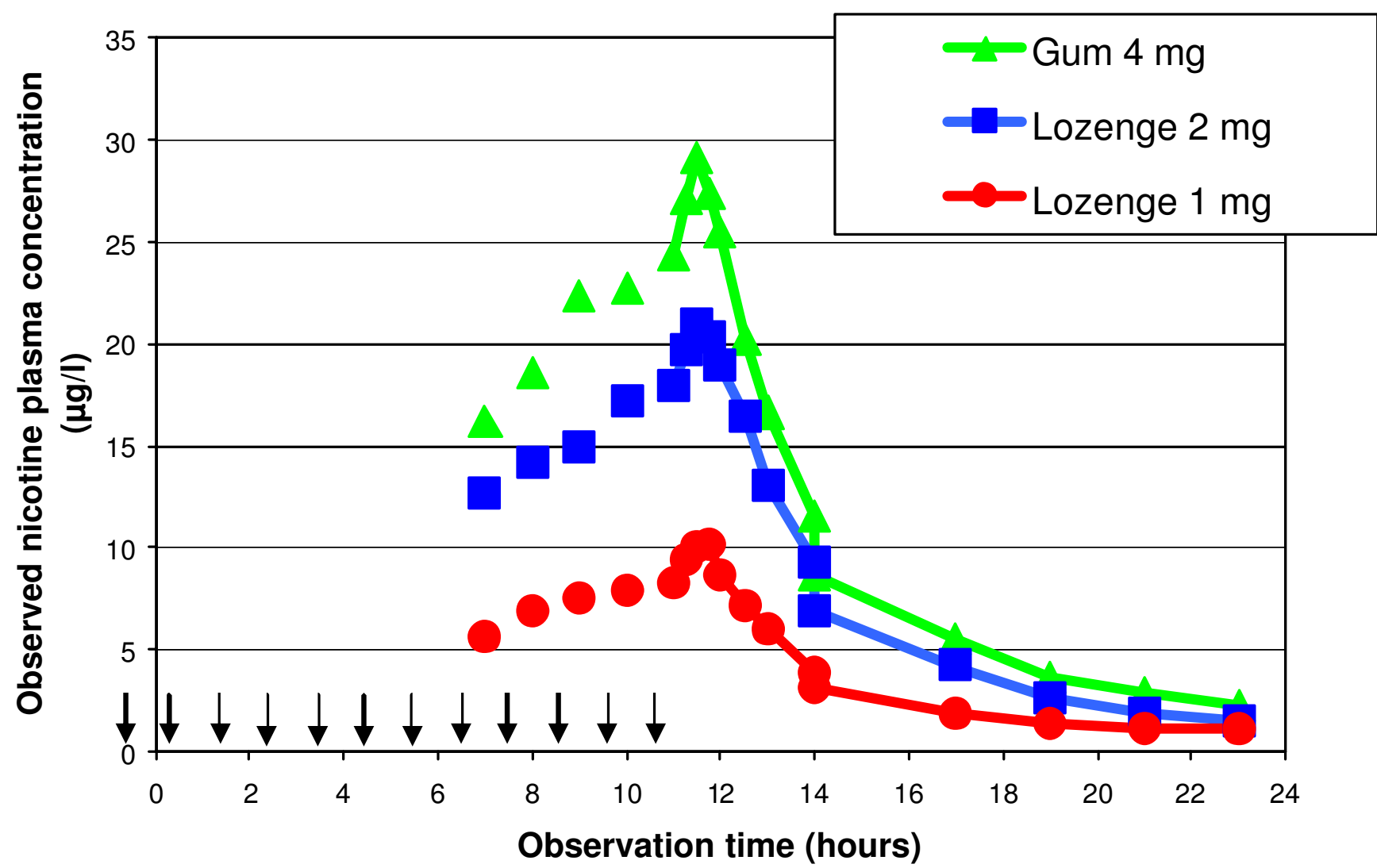

Figure 3

Nicotine plasma concentration after repeated intake of nicotine lozenges or gum (3 I subjects). Nicotine plasma concentrations were determined from blood samples of $3 \mathrm{I}$ volunteers drawn before hourly administration of I or 2 mg nicotine lozenge or $4 \mathrm{mg}$ nicotine gum (unconnected data points). Consecutive blood samples (connected data points) were drawn after administration of dose $12(\mathrm{t}=\mathrm{II} \mathrm{h})$.

\section{Efficacy of I mg lozenge for smoking cessation in phase 3 trials}

The two randomized placebo-controlled trials to assess the clinical efficacy of $1 \mathrm{mg}$ Nicotinell lozenge, involved approximately 900 subjects. For both trials, the demographic characteristics of enrolled subjects, including parameters related to past smoking history (years of smoking, number of cigarettes per day, exhaled CO, and urinary nicotine metabolite levels) were matched between groups (data not shown). The only important difference between the two studies was the level of patients' cigarette dependence at inclusion (see Methods).

The results for the primary efficacy criterion of the French trial on week 6 indicated a statistically significant increase in the number of subjects continuously abstinent from smoking with active lozenges, with an odds ratio (OR) for abstinence of 1.72 [95\% CI: 1.05-2.80] compared with placebo (Table 7). This result was in line with previously reported odds for quitting with NRT products in general [9] and a polacrilex lozenge formulation $2 \mathrm{mg}$ in particu- lar [16]. The full numbers about complete abstinence from week 2 are detailed in table 8 . When the less selective, secondary efficacy criterion was applied (complete or partial smoking abstinence on week 6), the OR for abstinence with the active lozenge was 2.18 [1.40-3.41], and statistically significant differences $(\mathrm{p}<0.05)$ between active and placebo lozenges in the percentage of abstinent smokers were found not only at week 6 , but also for the follow-up visit at week 12 (Table 7 and Figure 4). On week 26 , this difference was only significant for the subgroup of subjects previously smoking $>20$ cigarettes per day (data not shown). In addition, the evolution (compared to baseline) of the score for cessation-related withdrawal symptoms was determined, and increases proved to be less intense for subjects randomized to the active group ( $\mathrm{p}$ $<0.001$ ) than for those in the placebo group (Figure 5). Finally, there was no increased frequency of any side effects in the active group and vital signs control did not reveal any relevant differences between the two treatment groups. 
Table 6: PK parameters of nicotine in plasma after swallowing without sucking of increasing numbers of I mg lozenge $(\mathrm{mean} \pm \mathrm{SD}$; $\mathrm{n}=$ 8 per group)

\begin{tabular}{lccc}
\hline GrouplPK parameter & A & B & C \\
\cline { 2 - 4 } & 3 lozenges & 6 lozenges & 12 lozenges \\
\hline $\mathbf{C}_{\max }(\mathbf{n g} / \mathrm{ml})$ & $8.2 \pm 7.6$ & $16.9 \pm 11.8$ & $20.5 \pm 8.8$ \\
$\mathbf{t}_{\max }(\mathbf{h})$ & $2.7 \pm 2.8$ & $2.8 \pm 2.0$ & $2.2 \pm 1.4$ \\
AUC $_{10 \text { min-12 } \mathbf{h}}(\mathbf{h} . \mathbf{n g} / \mathrm{ml})$ & $37.0 \pm 27.2$ & $84.9 \pm 48.9$ & $103.1 \pm 58.6$ \\
\hline
\end{tabular}

PK parameters were not corrected for baseline plasma nicotine levels.

In the US trial, analysis for the primary efficacy criterion at week 6 also demonstrated a statistically significant superiority for active vs. placebo lozenges in the number of quitters who remained continuously abstinent on week 6 (OR $=2.87$ [95\% CI: 1.18-6.97]) (Table 8). The proportion of subjects continuously abstinent from week 2 through to week 12 was also significantly higher with active lozenge than with placebo lozenge (Table 8, Figure 6). However, the abstinence rates were lower than in the French trial, which might be due to patients' higher dependence levels at inclusion. Withdrawal symptoms, assessed as total craving and total mood scores, were reduced in the active group in comparison with the placebo group during the steady treatment period (up to week 6), with statistically significant differences in mean total craving scores at week $1(\mathrm{p}=0.03)$, and weeks 2 and $3(\mathrm{p}<0.01)$.

Overall, Nicotinell $1 \mathrm{mg}$ lozenges significantly increased the ratios of short-term abstinent from smoking patients, with no increase in side effects compared with placebo. Of interest, the mean consumption in the US trial, which included more highly dependent smokers than the French trial, consisted of 12.9 nicotine lozenges/day during the steady treatment phase (week 1-6), and decreased from 8.8 lozenges/day (week 7) to 3.3 lozenges/day (week 12) during the weaning phase. Corresponding amounts of lozenges/day in the French trial were 8.7 (week 1-6), 6.2 (week 7), and 1.9 (week 12). These numbers provided evidence for the self-titration behavior of smokers when using Nicotinell ${ }^{\circledast} 1 \mathrm{mg}$ lozenge, with subjects adjusting their intake to their individual needs.

\section{Discussion}

This review presents PK data obtained during the clinical development process of 1 and $2 \mathrm{mg}$ Nicotinell lozenges, which show that these formulations deliver significant amounts of nicotine, despite lower amounts of nicotinebase equivalents compared to the polacrilex $2 \mathrm{mg}$ chewing gum. In addition, we present clinical data, which demonstrate that these lozenges are effective and safe for use by smokers wanting to quit smoking.

The high addictiveness of tobacco smoking makes it difficult to quit without some form of additional help [30,31]. Pharmaceutical NRT, i.e. the administration of purified nicotine under controlled regimens to smokers in order to help them to stop smoking cigarettes, aims at alleviating craving for nicotine and thereby preventing rapid relapse. Accordingly, over the last 20 years, a body of experimental evidence has demonstrated that the chances for motivated smokers to successfully quit were roughly doubled when NRT products were used [9]. Nicotine for NRT is available

Table 7: Primary and secondary efficacy criteria: complete or partial abstinence during the 28 days preceding the 6-week visit (adopted from [17])

\begin{tabular}{|c|c|c|}
\hline \multirow[t]{2}{*}{ Group/Statistical results } & $\begin{array}{c}\text { Nicotinell }{ }^{\circledR} \\
\text { lozenge I mg }\end{array}$ & Placebo \\
\hline & $(n=2 I I)$ & $(n=222)$ \\
\hline Complete abstinence (\%) & $48(23 \%)$ & $32(14 \%)$ \\
\hline OR $[95 \% \mathrm{Cl}]$ & & \\
\hline Statistical significance & & \\
\hline Complete or partial abstinence (\%) & 68 (32\%) & $39(18 \%)$ \\
\hline OR $[95 \% \mathrm{Cl}]$ & & \\
\hline Statistical significance & & \\
\hline
\end{tabular}

Complete abstinence $=$ subjects declaring not to smoke + exhaled-breath $\mathrm{CO}<10 \mathrm{ppm}$. Partial abstinence $=$ subjects smoking $\leq \mathrm{I}$ cigarette/day and $\leq 7$ cigarettes/week + exhaled-breath $\mathrm{CO}<10$ ppm. 
Table 8: Complete abstinence from week 2 at each visit

\begin{tabular}{|c|c|c|c|c|c|c|c|}
\hline \multirow{2}{*}{\multicolumn{2}{|c|}{$\begin{array}{l}\text { Time since treatment started } \\
\text { French study (FTDN } 4 \text { to7) }\end{array}$}} & \multicolumn{2}{|c|}{6 weeks } & \multicolumn{2}{|c|}{12 weeks } & \multicolumn{2}{|c|}{26 weeks } \\
\hline & & \multicolumn{6}{|c|}{ Placebo $n=222$, Nicotinell Lozenge I $\mathrm{mg} \mathrm{n}=21 \mathrm{I}$} \\
\hline $\begin{array}{l}\text { Completely } \\
\text { abstinent }\end{array}$ & active & 48 & $22.7 \%$ & 28 & $13.3 \%$ & 25 & II.8\% \\
\hline $\mathbf{N}(\%)$ & placebo & 32 & | $4.4 \%$ & 20 & $9.0 \%$ & 18 & $8.1 \%$ \\
\hline OR $[95 \% \mathrm{Cl}]$ & & \multicolumn{2}{|c|}{$1.72[1.05-2.80]$} & \multicolumn{2}{|c|}{$1.47[0.82-2.65]$} & \multicolumn{2}{|c|}{$1.48[0.78-2.79]$} \\
\hline $\begin{array}{l}\text { Statistical } \\
\text { significance }\end{array}$ & & \multicolumn{2}{|c|}{$p=0.03$} & \multicolumn{2}{|c|}{$p=0.199$} & \multicolumn{2}{|c|}{$p=0.227$} \\
\hline $\begin{array}{l}\text { USA study } \\
(\text { FTND } \geq 6)\end{array}$ & & \multicolumn{6}{|c|}{ Placebo $n=230$, Nicotinell Lozenge I $\mathrm{mg} \mathrm{n}=230$} \\
\hline $\begin{array}{l}\text { Completely } \\
\text { abstinent }\end{array}$ & active & 19 & $8.3 \%$ & 11 & $4.8 \%$ & 8 & $3.5 \%$ \\
\hline $\mathbf{N}(\%)$ & placebo & 7 & $3.0 \%$ & 3 & $1.3 \%$ & 2 & $0.9 \%$ \\
\hline OR $[95 \% \mathrm{Cl}]$ & & \multicolumn{2}{|c|}{$2.87[1.18-6.97]$} & \multicolumn{2}{|c|}{$3.80[1.05-13.80]$} & \multicolumn{2}{|c|}{$4.11[0.83-19.55]$} \\
\hline $\begin{array}{l}\text { Statistical } \\
\text { significance }\end{array}$ & & \multicolumn{2}{|c|}{$p=0.02$} & \multicolumn{2}{|c|}{$p=0.03$} & \multicolumn{2}{|c|}{$p=0.06$} \\
\hline
\end{tabular}

Completely abstinent $=$ subjects declaring not to smoke + exhaled-breath $\mathrm{CO}<10 \mathrm{ppm}$

in a number of different pharmacological formulations, and lozenges are among the latest additions to the arsenal of NRT products $[16,22]$. Oral nicotine formulations present both advantages and inconveniences directly related to this route of administration: their major drawback, as compared with transdermal patches, is that repeated intake of the drug is necessary to achieve sustained blood nicotine levels. On the other hand, the versatility of acute dosage forms allows abstinent smokers to address temporary craving episodes, and gives them the possibility of a behavioral response somehow similar to the previous cigarette-linked gestures.

Oral nicotine formulations are the treatment of choice when abstinent smokers want to keep an active control in situations that may trigger smoking relapse, e.g. before stressful meetings or social events $[8,32]$. While worldwide the gum formulations are the most common oral NRT products, a number of disadvantages might render people reluctant to use them: incompatibility with dental works or temporomandibular joint pain, cultural or social acceptance and occurrence of AEs (e.g. hiccup or throat irritation) [33]. In this respect, lozenges present a valuable alternative as their use is more discrete and aesthetic.

Nicotine is best absorbed when it is in its non-ionized form, which rapidly crosses biomembranes. Accordingly, in the development of 1 and $2 \mathrm{mg}$ Nicotinell lozenges, particular attention has been paid to optimization of the alkalizing resin to obtain optimal nicotine release and absorption. The new formulations for lozenges were compared to 2 and $4 \mathrm{mg}$ nicotine polacrilex gum (Nicorette ${ }^{\circledast}$ ), which are pharmacologically well-characterized and were the first oral NRT product on the market $[15,26,34,35]$.

Comparison of PK parameters after a single dose of lozenge or gum showed that the amount of nicotine absorbed through $1 \mathrm{mg}$ Nicotinell lozenges is similar to that obtained via $2 \mathrm{mg}$ polacrilex gum, and that both formulations have comparable kinetics. In addition, doseconcentration proportionality between 1 and $2 \mathrm{mg}$ Nicotinell ${ }^{\circledR}$ lozenges was evident from PK results, with a net doubling of $\mathrm{C}_{\max }$ and AUC achieved with the $2 \mathrm{mg}$ formulation compared to the $1 \mathrm{mg}$ formulation. The discrepancy in gross nicotine delivery between Nicotinell $1 \mathrm{mg}$ lozenges and polacrilex $2 \mathrm{mg}$ gum in the single-dose study is only apparent and was not found in the latter studies, when the sucking pattern was adapted: lozenges are designed to be completely sucked out, whereas gum are known to retain a significant amount of nicotine within the resin $(28 \%$ and $47 \%$ of total nicotine content, respectively for $4 \mathrm{mg}$ and $2 \mathrm{mg}$ gum, i.e. approximately $1 \mathrm{mg}$ nicotine for both strenght) [25]. Besides, variations among individuals, probably due to differences in mastication intensity, chewing techniques or oral $\mathrm{pH}$ could explain some of the differences [26].

Comparable absorption of nicotine from $1 \mathrm{mg}$ lozenges and $2 \mathrm{mg}$ gum was confirmed in the first multiple dose trial, performed to compare the PK profile of both formulations under conditions close to real use of NRT products. At steady state, all assessed PK parameters were similar and formal bioequivalence using the standard BAR [0.8-1.25] was demonstrated for $\mathrm{C}_{\max }$ and AUC. In 


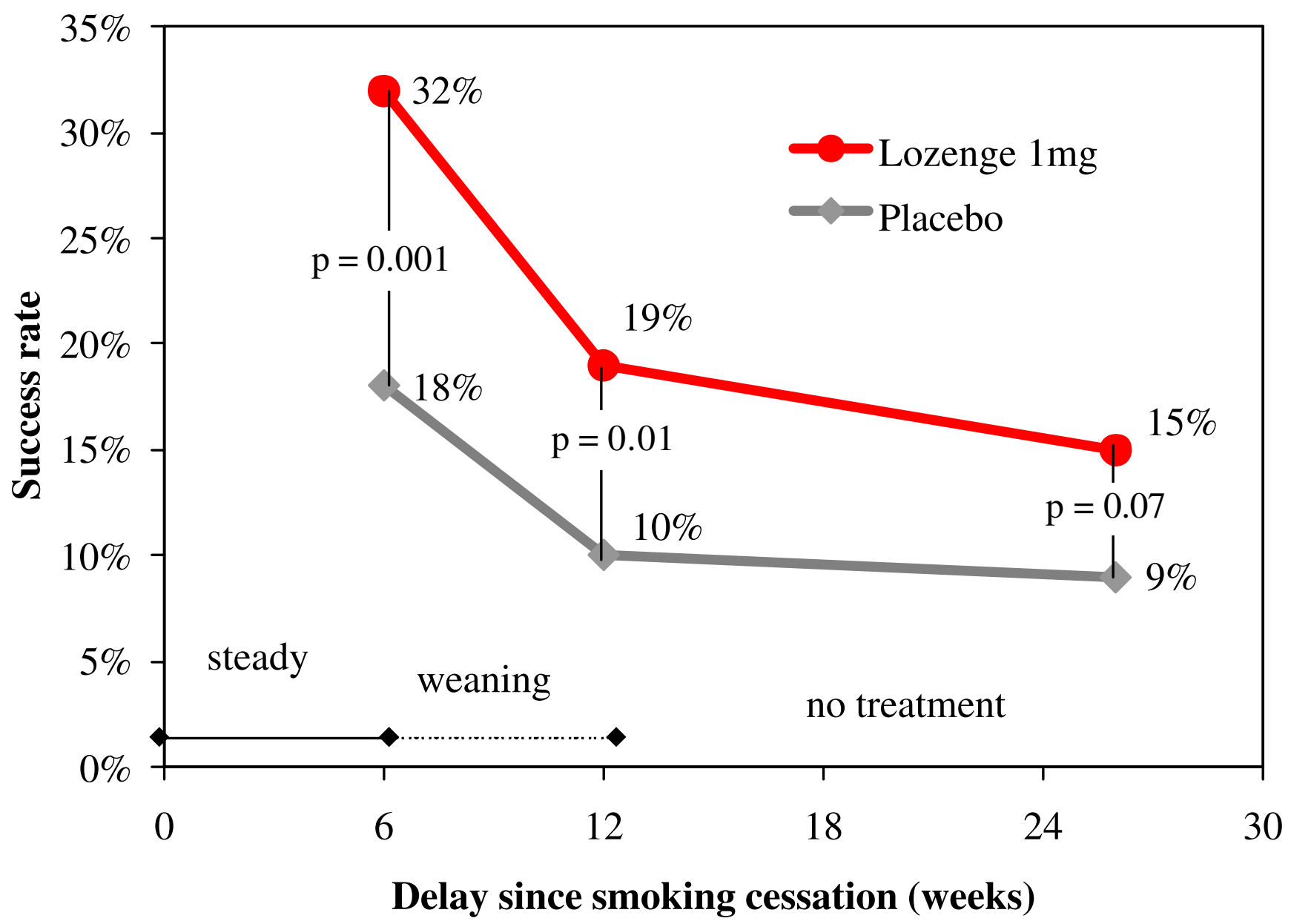

Figure 4

Smoking cessation success rates among users of I mg nicotine lozenges (moderately dependent patients) (adopted from [ I7]). The rate of fully (no cigarettes) or partially ( $\leq$ I cigarette/day and $\leq 7$ cigarettes/week) abstinent subjects using I mg nicotine lozenges for abrupt quitting over the first 6 months of the French efficacy trial.

the second multiple dose trial the dose-concentration proportionality between Nicotinell ${ }^{\circledR} 1$ and 2 mg lozenges was confirmed, with $2 \mathrm{mg}$ lozenges inducing plasma concentrations intermediate between those obtained with $1 \mathrm{mg}$ lozenges and $4 \mathrm{mg}$ polacrilex gum.

Accordingly, the systemic exposure to nicotine with Nicotinell lozenges and with Nicorette gum, under conditions reflecting the intended use, could be ranked as follows: 4 mg polacrilex gum $>2 \mathrm{mg}$ Nicotinell lozenge $>1 \mathrm{mg}$ Nicotinell lozenge $=2 \mathrm{mg}$ polacrilex gum.

The criteria applied to evaluate bioequivalence between different NRT products can give rise to discussion. Indeed, even when the standard BAR [0.8-1.25] does not argue in favor of bioequivalence, the enlarged BAR [0.7-1.43] is relevant to assess bioequivalence between two oral NRT formulations. This reasoning is based on the particular behavior encountered in smokers: smokers regulate their intake of nicotine by the number of cigarettes they smoke and their inhaling mode. They achieve the desired effects and minimize withdrawal symptoms by adjusting an individual "optimal" blood level of nicotine [27]. Similarly, the intake of NRT oral or nasal products is subject to selftitration: clinical studies showed that the use of nicotine gum or nasal spray followed a principle of self-titration similar to that observed with cigarettes, with an ad-libitum schedule resulting in more constant blood levels than a fixed schedule $[28,29]$. It can reasonably be assumed that nicotine self-titration behavior is found with all cessation products administered in multiple doses per day and favors individual adjustment of the dose to achieve the desired effect. In this respect, bioequivalence using the enlarged BAR [0.7-1.43] was achieved in the multipledose study comparing $1 \mathrm{mg}$ lozenge with $2 \mathrm{mg}$ gum, even when no adjustment for increasing nicotine release from 


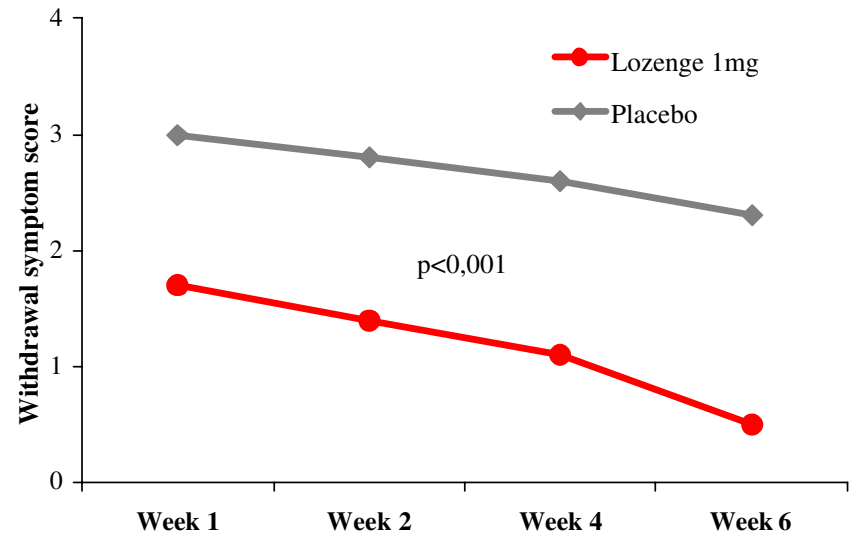

Figure 5

Withdrawal symptom score (change vs. baseline) among users of I mg nicotine lozenges (adopted from [18]).

the gum with time was applied (90\% CI [lozenge/gum] for $\mathrm{C}_{\max }$ : 0.76-0.93; for $\left.\mathrm{AUC}_{11-12}: 0.75-0.91\right)$.

The safety of 1 and $2 \mathrm{mg}$ Nicotinell lozenges can be assessed based on the observations of the 70 healthy adult male smokers enrolled in the PK trials. In this study population exposed to single or multiple doses of lozenges, no serious or unexpected AEs and no changes in physical examination, vital signs, cardiovascular parameters and laboratory values were observed. Reported AEs were mild or (at worst) moderate in intensity, transient and completely reversible. This good tolerability of lozenges is in line with safety results reported in previous clinical trials with nicotine-polacrilex lozenges $[16,22,36]$. Even during the complementary safety trial, with subjects swallowing up to 12 lozenges at once, no serious or lasting AEs were reported and the overall tolerability was rated as excellent. Finally, the data from the two large phase 3 efficacy trials further confirmed the safety profile of the nicotine lozenges, as there were no relevant differences in $\mathrm{AE}$ frequency or nature between placebo and active groups. In addition, the vast majority of the reported AEs could also be attributed to the effects of abrupt smoking cessation.

The efficacy trials were designed to provide sufficient power for the statistical analysis of the primary efficacy criterion: controlled continuous smoking abstinence during the 28 days preceding the visit scheduled at week 6 . This primary efficacy criterion was severe, as it obliged subjects

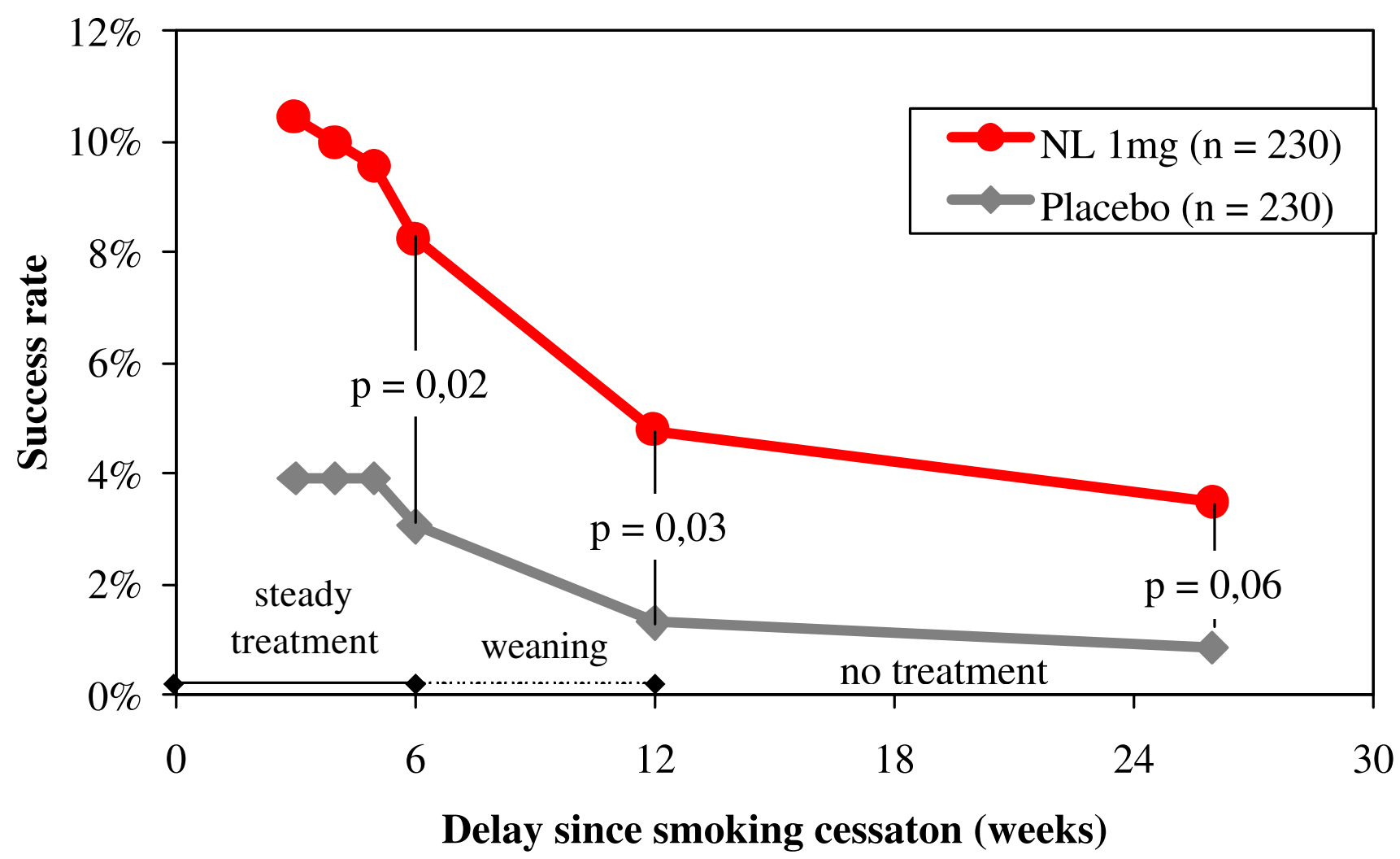

Figure 6

Smoking cessation success rates among users of I $\mathbf{~ m g}$ nicotine lozenges (highly dependent patients). The rate of completely abstinent subjects using I mg nicotine lozenges for abrupt quitting over the first 6 months of the U.S. efficacy trial. 
to stop smoking completely before the end of the second week of treatment, compared with 3-week to 12-month reported for some nicotine gum trials [9]. However, the short treatment period seems to be more in line with "real world" use by consumers [37]. In addition, the weaning phase of 6 weeks (from week 7 to 12, after which no more lozenges were supplied) was also relatively short compared with some published nicotine gum trials, and subjects starting to smoke again were excluded from followup, regardless of their ensuing performance. These particularities must be remembered when interpreting the efficacy results. Further, in both trials, no specific behavioral counseling or support was provided to the studied populations. Notwithstanding these facts, the statistically significant differences in short-term abstinence rates as well as the odds for successful quitting with lozenge vs. placebo did underscore the efficacy of $1 \mathrm{mg}$ nicotine lozenge as a smoking cessation aid.

Comparative analysis of PK results of the 1 and $2 \mathrm{mg} \mathrm{loz}$ enge showed that at steady state $C_{\max }$ was approximately 11 and $23 \mathrm{ng} / \mathrm{ml}$, respectively. Notably, these levels are on the lower end of the range of blood nicotine levels (10-50 $\mathrm{ng} / \mathrm{ml}$ ) observed in smokers at steady state. As nicotine underdosing during smoking cessation is generally considered to increase the risk for failure in nicotine dependent patients [13,37], the $2 \mathrm{mg}$ Nicotinell lozenge may provide increased efficacy for heavily to very heavily dependent smokers, whereas the $1 \mathrm{mg}$ dose may fulfill the needs of light to moderate dependent smokers. Considering a possible abuse potential of the lozenges, which is inherent to all NRT products administered in multiple doses per day, it should be noted that in the French efficacy trial urinary cotinine levels decreased not only in the population of abstinent subjects receiving placebo, but also in the population receiving $1 \mathrm{mg}$ lozenges, thus clearly indicating that at least short-medium term quitters do not overdose the product.

\section{Conclusion}

The data presented in this review demonstrate high nicotine bioavailability, excellent safety profile and proven short-term efficacy of Nicotinell lozenges. At nominal equivalent doses 1 and $2 \mathrm{mg}$ Nicotinell lozenges were shown to deliver larger amounts of bioavailable nicotine compared to the nicotine-polacrilex gum. Thus, Nicotinell $1 \mathrm{mg}$ lozenge was bioequivalent to $2 \mathrm{mg}$ polacrilex gum following single as well as multiple doses, whereas the 2 mg lozenge provided nicotine levels between those of the 2 and the $4 \mathrm{mg}$ polacrilex gum. Accordingly, the systemic exposure to nicotine could be ranked: $4 \mathrm{mg}$ polacrilex gum $>2 \mathrm{mg}$ Nicotinell lozenge $>1 \mathrm{mg}$ Nicotinell lozenge $=2 \mathrm{mg}$ polacrilex gum
All AEs observed during the clinical development were mild or moderate in severity, transient and completely reversible. With respect to efficacy in smoking cessation, significantly higher short-term abstinence rates (continuous abstinence from week 2, assessed on week 6) were achieved with lozenge compared to placebo. In conclusion, Nicotinell lozenges offer a valuable addition to the therapeutic armamentarium available for smoking cessation.

\section{Competing interests}

J.-L. Kienzler and A. Callens are employees of Novartis Consumer Health S.A. which produce and distribute nicotine replacement products. All research trials were funded by Novartis Consumer Health.

\section{Authors' contributions}

$\mathrm{BD}$ was the principal investigator of the French phase 3 efficacy trial. MN participated to the Novartis Consumer Heath smoking cessation activities in the US. JLK and AC supervised and coordinated the clinical development of the Nicotinell ${ }^{\circledast}$ lozenges. All authors read and approved the final manuscript.

\section{Acknowledgements}

The authors thank Thomas Moll, PhD, from HPM (Geneva) S.A. who provided medical writing services on behalf of Novartis Consumer Health S.A., Nyon, Switzerland.

The authors also wish to thank all the people involved in the conduct of the trials presented in this review, especially the investigators and CRO staff members.

\section{References}

I. Hecht SS: Tobacco smoke carcinogens and lung cancer. J Natl Cancer Inst 1999, 9 | ( 1 4): | | 94- 1210.

2. Chen Z, Boreham J: Smoking and cardiovascular disease. Semin Vasc Med 2002, 2(3):243-252.

3. Kamholz SL: Pulmonary and cardiovascular consequences of smoking. Med Clin North Am 2004, 88(6): I 4I5- 1430. ix-X

4. West R, DiMarino ME, Gitchell J, McNeill A: Impact of UK policy initiatives on use of medicines to aid smoking cessation. Tob Control 2005, 14(3):|66-|7|.

5. Shiffman S, Gitchell J, Pinney JM, Burton SL, Kemper KE, Lara EA: Public health benefit of over-the-counter nicotine medications. Tob Control 1997, 6(4):306-310.

6. Law MR, Hackshaw AK: Environmental tobacco smoke. Br Med Bull 1996, 52(I):22-34.

7. Schroeder SA: What to do with a patient who smokes. JAMA 2005, 294(4):482-487.

8. Henningfield JE, Fant RV, Buchhalter AR, Stitzer ML: Pharmacotherapy for nicotine dependence. CA Cancer J Clin 2005, 55(5):28I-299.

9. Silagy C, Lancaster T, Stead L, Mant D, Fowler G: Nicotine replacement therapy for smoking cessation. Cochrane Database Syst Rev 2004:CD000146.

10. McNeill A, Foulds J, Bates C: Regulation of nicotine replacement therapies (NRT): a critique of current practice. Addiction 200I, 96(I 2): 1757-1768.

II. WHO Europe, McNeill A, Hendrie A: Regulation of nicotine replacement therapies: an expert consensus. Copenhagen 200 I [http://www.euro.who.int/document/e74522.pdf].

12. Fiore MC, Bailey WC, Cohen SJ, Dorfman SF, Goldstein MG, Gritz ER, Heyman RB, Jaen CR, Kottke TE, Lando HA, et al: A clinical practice guideline for treating tobacco use and dependence: 
A US Public Health Service report. JAMA 2000, 283(24):3244-3254.

13. Shiffman S, Fant RV, Buchhalter AR, Gitchell JG, Henningfield JE: Nicotine delivery systems. Expert Opin Drug Deliv 2005, 2(3):563-577.

14. Le Houezec J: Role of nicotine pharmacokinetics in nicotine addiction and nicotine replacement therapy: a review. Int J Tuberc Lung Dis 2003, 7(9):8II-8I9.

15. Burton SL, Gitchell JG, Shiffman S: Use of FDA-approved pharmacological treatments for tobacco dependence - United States, 1984-1998. MMWR Morb Mortal Wkly Rep 2000, 49(29):665-668

16. Shiffman S, Dresler CM, Hajek P, Gilburt SJ, Targett DA, Strahs KR Efficacy of a nicotine lozenge for smoking cessation. Arch Intern Med 2002, I 62(I I): 1267-1276.

17. Dautzenberg B, Ruff F, Vaucher M, Maillon P, Jacob N, Kienzler JL Rentsch D, Callens A: First demonstration of the good efficacyl safety ratio of Nicotinell(R) I mg lozenge (NL I mg), a new form of nicotine substitution, by randomised clinical trial [abstract]. Eur Respir J 200I:s I2.

18. Dautzenberg B, Vaucher M, Maillon P, Peiffer G, Toulouse F, Lagrue G, Jacob N, Kienzler JL, Rentsch D, Callens A: [Efficacy and tolerance of a I mg nicotine lozenge in smoking cessation. Randomized double-blind trial]. Le courrier des addictions 2005, $7(1): 7-12$.

19. Shiffman S, Di Marino ME, Pillitteri JL: The effectiveness of nicotine patch and nicotine lozenge in very heavy smokers. J Subst Abuse Treat 2005, 28(I):49-55.

20. Shiffman S: Nicotine lozenge efficacy in light smokers. Drug Alcohol Depend 2005, 77(3):3 I I-3 I4.

21. Shiffman S, Dresler CM, Rohay JM: Successful treatment with a nicotine lozenge of smokers with prior failure in pharmacological therapy. Addiction 2004, 99(I):83-92.

22. Demazieres A, Luthringer R, Coppel E, Gilles C, Fleury C, Roegel JC, Delarue A, Laur C, Lagrue G: Ability of a new oral nicotine substitute to reduce smoking urge in moderate smokers. Addict Behav 2005, 3 I (3):537-543.

23. Choi JH, Dresler CM, Norton MR, Strahs KR: Pharmacokinetics of a nicotine polacrilex lozenge. Nicotine Tob Res 2003, 5(5):635-644.

24. Heatherton TF, Kozlowski LT, Frecker RC, Fagerstrom KO: The Fagerstrom Test for Nicotine Dependence: a revision of the Fagerstrom Tolerance Questionnaire. $\mathrm{Br}$ 」 Addict |991, 86(9): I I $19-|| 27$

25. Benowitz N, Porchet H, Jacob P: Pharmacokinetics, metabolism and pharmacodynamics of nicotine. In Nicotine psychopharmacology: molecular, cellular and behavioral aspects Edited by: Wonnacott S, Russell MA, Stolerman IP. Oxford: Oxford University Press; 1990:112-157.

26. Benowitz NL, Jacob P 3rd, Savanapridi C: Determinants of nicotine intake while chewing nicotine polacrilex gum. Clin Pharmacol Ther 1987, 4 I(4):467-473.

27. Benowitz NL: Pharmacology of nicotine: addiction and therapeutics. Annu Rev Pharmacol Toxicol 1996, 36:597-6I3.

28. Lunell E, Molander L, Andersson M: Relative bioavailability of nicotine from a nasal spray in infectious rhinitis and after use of a topical decongestant. Eur I Clin Pharmacol I995, 48(I):7I-75.

29. Fagerstrom KO: Efficacy of nicotine chewing gum: a review. Prog Clin Biol Res 1988, 26I:109-128.

30. Henningfield JE, Stapleton JM, Benowitz NL, Grayson RF, London ED: Higher levels of nicotine in arterial than in venous blood after cigarette smoking. Drug Alcohol Depend 1993, 33(I):23-29.

31. George TP, O'Malley SS: Current pharmacological treatments for nicotine dependence. Trends Pharmacol Sci 2004, 25( I):42-48.

32. Cohen LM, Collins FL Jr, Britt DM: The effect of chewing gum on tobacco withdrawal. Addict Behav 1997, 22(6):769-773.

33. Murray RP, Bailey WC, Daniels K, Bjornson WM, Kurnow K, Connett JE, Nides MA, Kiley JP: Safety of nicotine polacrilex gum used by 3,094 participants in the Lung Health Study. Chest 1996, 109(2):438-445.

34. Hu T, Sung HY, Keeler TE, Marciniak M: Cigarette consumption and sales of nicotine replacement products. Tob Control 2000, 9(Suppl 2):1160-63.

35. Tonnesen P, Fryd V, Hansen M, Helsted J, Gunnersen AB, Forchammer $\mathrm{H}$, Stockner M: Two and four mg nicotine chewing gum and group counselling in smoking cessation: an open, rand- omized, controlled trial with a 22 month follow-up. Addict Behav 1988, I3(1): 17-27.

36. Marsh HS, Dresler CM, Choi JH, Targett DA, Gamble ML, Strahs KR: Safety profile of a nicotine lozenge compared with that of nicotine gum in adult smokers with underlying medical conditions: a I 2-week, randomized, open-label study. Clin Ther 2005, 27( I 0): I57| - I587.

37. Shiffman S, Hughes JR, Di Marino ME, Sweeney CT: Patterns of over-the-counter nicotine gum use: persistent use and concurrent smoking. Addiction 2003, 98( I 2): 1747- 1753.

\section{Pre-publication history}

The pre-publication history for this paper can be accessed here:

http://www.biomedcentral.com/1472-6904/7/11/prepub
Publish with Biomed Central and every scientist can read your work free of charge

"BioMed Central will be the most significant development for disseminating the results of biomedical research in our lifetime. "

Sir Paul Nurse, Cancer Research UK

Your research papers will be:

- available free of charge to the entire biomedical community

- peer reviewed and published immediately upon acceptance

- cited in PubMed and archived on PubMed Central

- yours - you keep the copyright 